\title{
+RIBEIRA: PROJETO DE REVITALIZAÇÃO DO BAIRRO DA RIBEIRA EM NATAL/RN
}

+RIBEIRA: PROYECTO DE REVITALIZACIÓN DEL BAIRRO DE LA RIBEIRA EN NATAL/RN

+RIBEIRA: REVITALIZATION PROJECT OF THE RIBEIRA NEIGHBORHOOD IN NATAL/RN

CAVALCANTE, EUNÁDIA SILVA

Professora do curso de Arquitetura e Urbanismo da UFRN, eunadiacavalcante@gmail.com

MARQUES, EMÍLIO SABRY AZAR

Estudante de Arquitetura e Urbanismo,UFRN, emilio.sabry@gmail.com

SAMPAIO, ANA LÍGIA PESSOA

Bacharel em Arquitetura e Urbanismo, Mestranda em Engenharia Civil, UFRN, analigiasampaio@hotmail.com

CARDOSO, RENATA DE LIMA ANDRADE

Bacharel em Arquitetura e Urbanismo, UFRN, renatalima_ac@hotmail.com

LIRA, FERNANDA OLÍMPIO DE

Estudante de Arquitetura e Urbanismo,UFRN, fernanda.lira@ufrn.abea.arq.br

TRINDADE, LARISSA SOARES

Bacharel em Design, UFRN, larissasoares1987@yahoo.com.br

NASCIMENTO, JOSÉ BRUNO PRIMO DO

Bacharel em Engenharia Civil, UFRN, josebrunoprimo@gmail.com

\section{INTRODUÇÃO}

O Centro Histórico de Natal, capital do Rio Grande do Norte, foi tombado pelo IPHAN em 2010 e é constituído pelos bairros Ribeira, Cidade Alta e Rocas que se encontram em estado degradação física e com insuficiente assistência do poder público. A Ribeira, segundo bairro mais antigo de Natal, tem sua história ligada ao rio e ao comércio (Figura 1). A sua localização estratégica tornou-a protagonista em eventos importantes da história da cidade, mas, hoje, sofre com o esquecimento da população. O bairro parece estar ilhado da vida moderna, mesmo sendo facilmente acessado de qualquer ponto da cidade.

Historicamente plural, mas, atualmente, reduzida à sua função institucional e de serviços pelo ideário popular, poucos lembram do papel singular da Ribeira durante a Segunda Guerra Mundial; do seu ar boêmio que inspirou tantas histórias; seu magnífico pôr-do-sol e a profunda conexão com o rio Potengi, hoje, fechados pelo porto e por decks particulares. Mais do que tudo, onde estão aqueles moradores que, de identidade tão marcante, tinham rixa com os que viviam na Cidade Alta? Os Canguleiros? Queremos trazê-los de volta.

Foi nesse sentido que o projeto +RIBEIRA buscou evidenciar que há muito mais na Ribeira do que as pessoas conhecem, nos preocupando em a reconectar com a dinâmica da cidade, da qual vai se afastando desde a década de 1980, e com ela mesma, entrando na rota dos habitantes e dos turistas não apenas para resolver 
Cavalcante, E. S.; Marques, E. S. A.; Sampaio, A. L. P.; Cardoso, R. L. A.; Lira, F. O.; Trindade, L. S.; Nascimento, J. B. P.

pendências devido ao seu perfil institucional, mas para a usufruir. A ideia foi resgatar a identidade do bairro e de seus habitantes, além de trazer novos; variar os usos; propor o reconhecimento e a conexão de seus atrativos materiais, imateriais e seus espaços verdes, completamente ilhados pelo tempo; e abrir o bairro novamente para o rio, tornando-o mais atraente para que as pessoas possam ocupá-lo.

$\mathrm{O}+$ Ribeira (Figura 2), pois, tem como proposta a retomada do aspecto identitário do bairro, utilizando a rede de pesca como conceito. Cada nó representa um ponto importante no lugar e as linhas são necessárias para conectá-los. Seus bens históricos, seu ar boêmio, seus espaços verdes e seus pontos de ligação com o rio são os nós dessa rede de reconhecimento que propomos para a Ribeira. Evidenciar esses nós e linhas é essencial para conectar a região à dinâmica da cidade e colocá-la como polo turístico e cultural, atraindo novos usuários e moradores. Sendo assim, diversidade é uma palavra chave no projeto. Diferentes usos, acessos e modais tornam-se necessários para instigar mais pessoas a vivenciar as diferentes facetas do bairro.

Figura 1: Ribeira e Rio Potengi

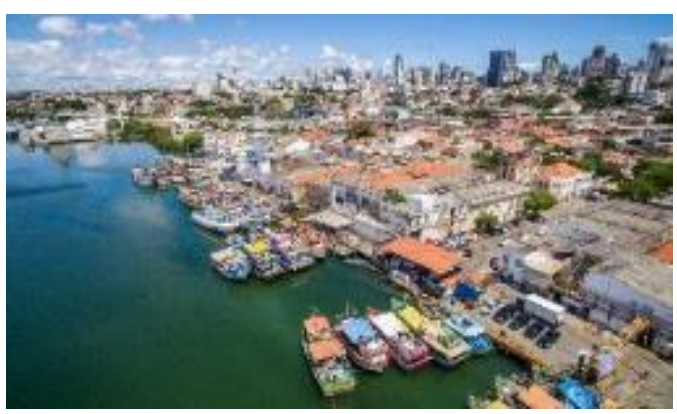

Fonte: Concurso do BID UrbanLAB.
Figura 2: Logomarca do grupo

\section{tRibeina \\ Descubra os circuitos culturais}

Fonte: Elaborado pelo grupo.

Foi proposto o reuso de edificações abandonadas e a criação de rotas para resgatar a história e incentivar a ocupação de seus espaços. Sendo as rotas boêmia, histórica, verde e o percurso do rio. Esses circuitos, antes de tudo, dão unidade e sentido aos eixos do bairro, estimulando o seu percurso completo e esclarecendo a importância e as potencialidades presentes na região. Esses caminhos são totalmente conectados através dos modais de transporte propostos como o hidrobus, a bicicleta e o ônibus. Junto a isso, uma nova identidade visual para o bairro é sugerida, tornando a linguagem arquitetônica e paisagística de fácil compreensão. O redesenho de vias e espaços públicos visam priorizar os pedestres, ciclistas e o transporte público. A expansão dos espaços públicos valoriza a arborização e amplia espaços verdes, melhorando, também, o conforto térmico da área, considerando que a Ribeira é $2^{\circ} \mathrm{C}$ mais quente que o resto da cidade, segundo Araújo (2004). As propostas colocadas nesse artigo são baseadas em análises críticas realizadas pela equipe sobre a área de intervenção projetual.

\section{PROJETO}

\subsection{IDENTIFICAÇÃO DOS PROBLEMAS E CONFLITOS}

Para o desenvolvimento da proposta +RIBEIRA, primeiro, foi necessário entender as relações existentes e consolidadas no tecido do bairro, as demandas e potencialidades da região, os conflitos atuais, bem como perceber o desenvolvimento da Ribeira como bairro, considerando a sua história e o seu contexto.

Em uma primeira análise percebeu-se um esvaziamento da população residente do bairro dentro da área de intervenção. A maior parte dos moradores dessa porção da Ribeira está residindo em Habitação de Interesse Social, tendo sido removida das margens do rio em decorrência de desapropriação para ampliação do porto. Além disso, a falta de espaços públicos que possibilite vitalidade na região é evidentemente marcante, com ausência de arborização e utilização dos imóveis desocupados. Identificou-se que a falta de conexão com rio Potengi é uma contradição histórica da Ribeira, pois, além do bairro desenvolver-se ao longo do rio, sempre teve a atividade pesqueira como parte importante da sua identidade - persistindo até hoje, seja por meio da pesca artesanal, seja através de empresas formalizadas. Somado a isso, percebe-se, no bairro, outros dois usos consolidados atualmente: o uso institucional ao longo dos horários comerciais; e o uso boêmio e a diversão noturna em boates e casas de shows, principalmente ao longo da Rua Chile.

Ademais, com respeito a questão viária, verificou-se a dificuldade de acesso a algumas localidades da área de intervenção. As rotas de ônibus utilizam as principais vias, especialmente, em virtude das dimensões do 
Cavalcante, E. S.; Marques, E. S. A.; Sampaio, A. L. P.; Cardoso, R. L. A.; Lira, F. O.; Trindade, L. S.; Nascimento, J. B. P.

leito das ruas; não há espaço destinado para ciclistas; muito do percurso interno do bairro deve ser resolvido a pé - com calçadas muitas vezes inadequadas - ou com veículo particular - gerando problemas com estacionamento.

A importância histórica da Ribeira é marcante com os diferentes estilos arquitetônicos e por ter legislação específica de preservação do patrimônio. É senso comum na cidade do Natal que esse bairro tem relevância cultural e até mesmo consolida parte da identidade natalense. Contudo, para a compreensão da equipe, ficou evidente: que a Ribeira se apresenta como um bairro fragmentado (tanto em usos e atividades, como em suas conexões de acesso interna e externa ao bairro); que não reconhece mais parte da sua identidade local; que sofre com o esvaziamento, assim como outras regiões centrais de cidades brasileiras.

\subsection{DESENVOLVIMENTO DA PROPOSTA}

Com o conceito de conexão o projeto tenta responder às demandas identificadas anteriormente: carência de elementos que reforcem a identidade do bairro; baixa conexão e integração intra e entre bairros; e o esvaziamento urbano. Para isso, somou-se a problemática da questão do financiamento para políticas urbanas. Partiu-se da ideia de conectar a Ribeira, primeiramente, com ela mesma para então ser integrada com a cidade. Desta forma, foram propostas quatro rotas que possibilitassem valorizar todas as diferentes características do bairro e evidenciar o potencial turístico da área, integrando-a com a dinâmica da cidade (Figura 3).

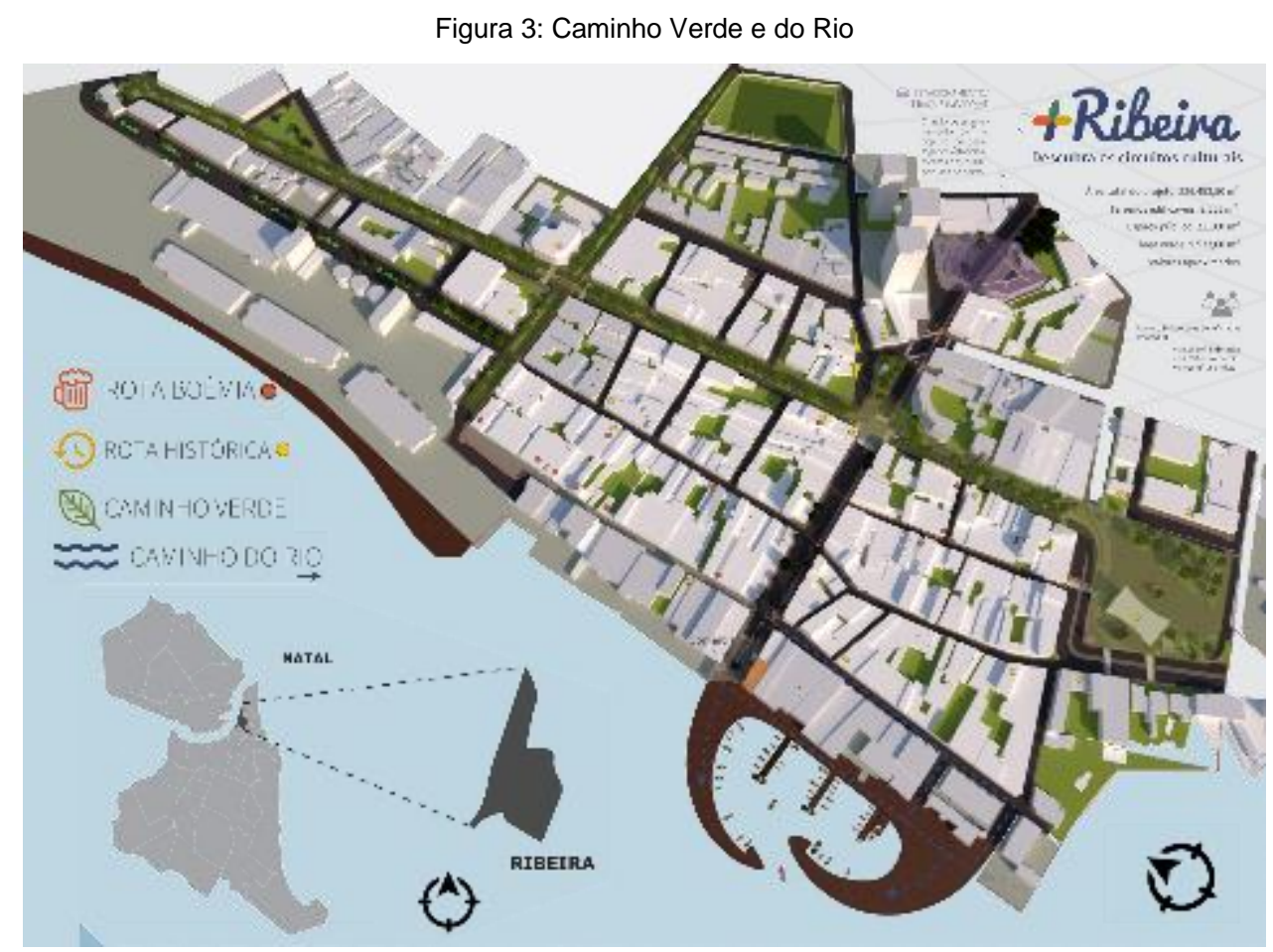

Fonte: Elaborado pelo grupo.

As rotas e caminhos propostos e que serão aqui detalhados são:

- Caminho Verde (Figura 4 - em verde):

Conexão das praças e espaços verdes da área, por meio do redesenho das principais ruas do bairro, com criação de calçadas largas e espaços de permanência;

- Caminho do Rio (Figura 4 - em azul):

Criação de um deck interligando as aberturas e de um píer para o atracamento dos barcos;

- Rota Histórica (Figura 5):

Comunicação visual sobre as edificações, com informações sobre o histórico dos bens;

- Rota Boêmia (Figura 6):

Identificação de espaços de cultura e lazer, criando um percurso de resgate a boemia da Ribeira.

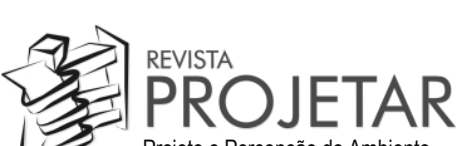


Figura 4: Caminho Verde e do Rio

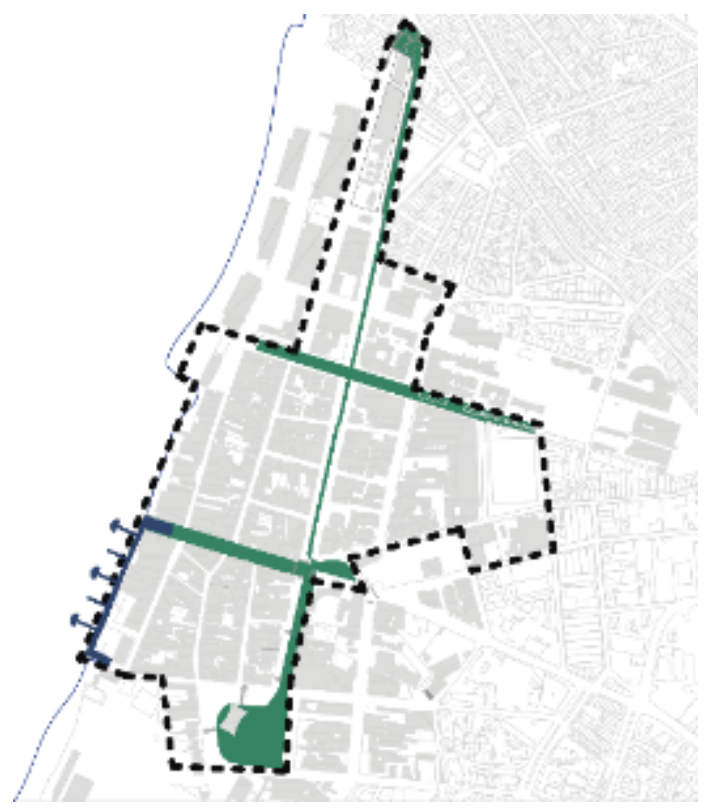

Fonte: Elaborado pelo grupo.

Figura 6: Rota Boêmia

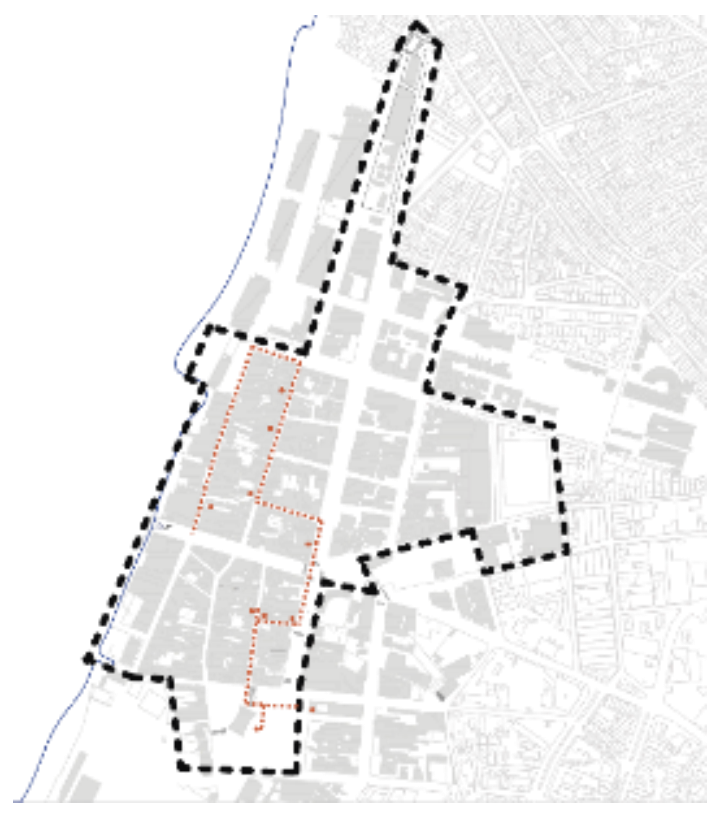

Fonte: Elaborado pelo grupo.
Figura 5: Rota Histórica

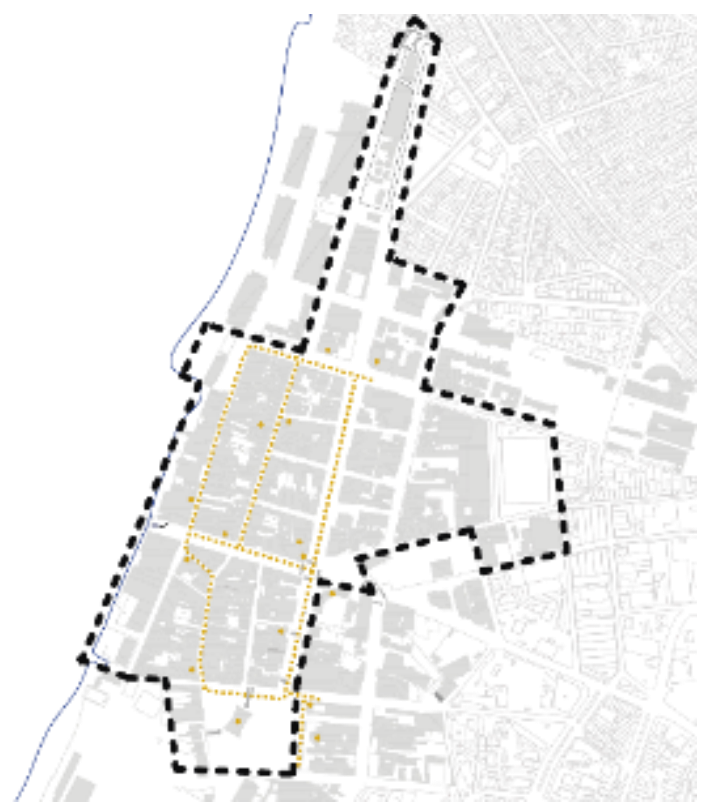

Fonte: Elaborado pelo grupo.

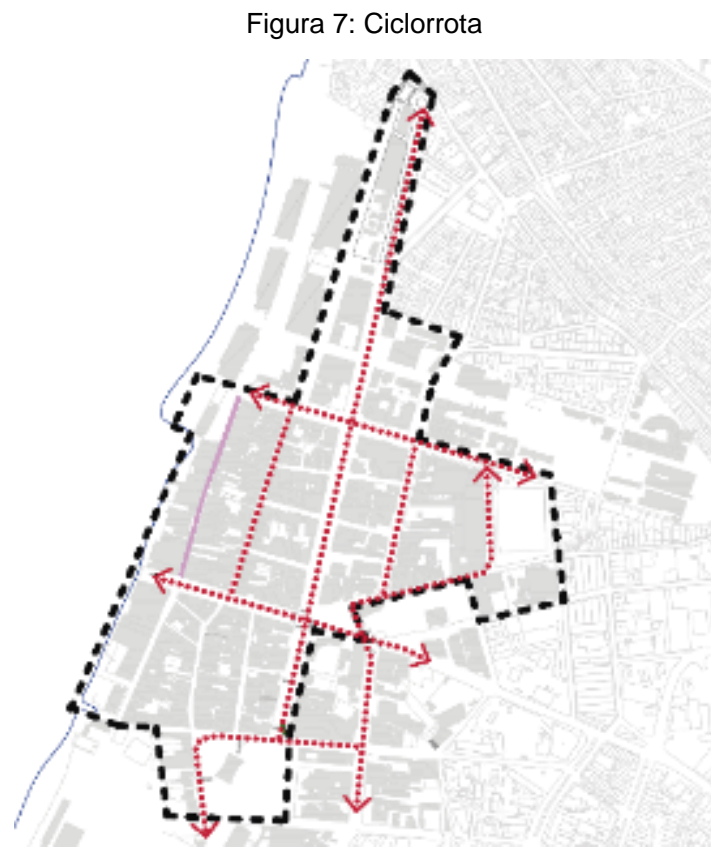

Fonte: Elaborado pelo grupo.

Devido às dimensões da via, optou-se por manter as rotas existentes dos ônibus. $O$ transporte ativo foi favorecido, diversificando-se os modais. Foram implementadas ciclorrotas (Figuras 7, 8 e 9), facilitando a integração dentro do bairro e trabalhando junto com o hidrobus como opções ao veículo particular. A proposta de um hidrobus (Figura 10), ligando a Ribeira com outras partes à beira rio, incluindo a Zona Norte, foi uma alternativa para facilitar a locomoção das pessoas para o bairro, tornando-o um ponto de distribuição de passageiros para diversos pontos de Natal. 
Cavalcante, E. S.; Marques, E. S. A.; Sampaio, A. L. P.; Cardoso, R. L. A.; Lira, F. O.; Trindade, L. S.; Nascimento, J. B. P.

Figura 8: Visualização do cruzamento Av. Duque de Caxias com Rua Sachet

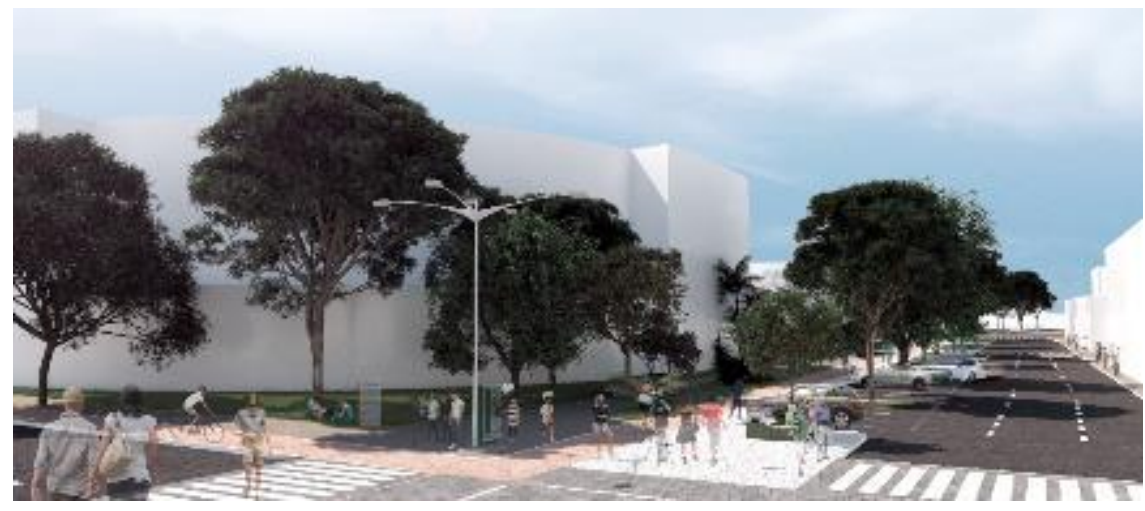

Fonte: Elaborado pelo grupo.

Figura 9: Detalhe - Av. Duque de Caxias com Esplanada Silva Jardim

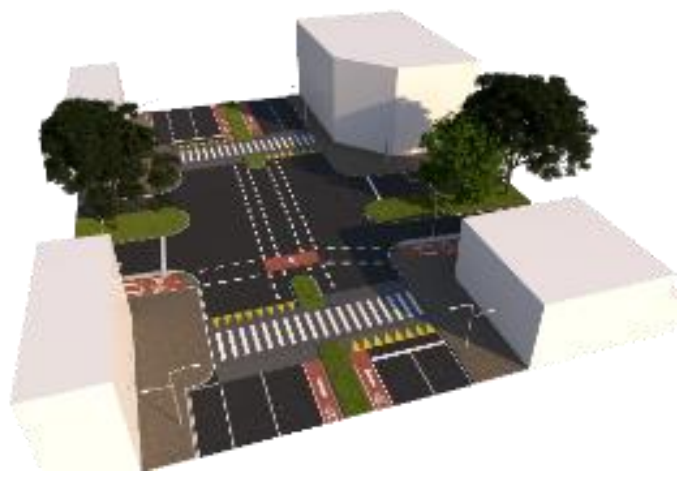

Fonte: Elaborado pelo grupo.
Figura 10: Rota do hidrobus

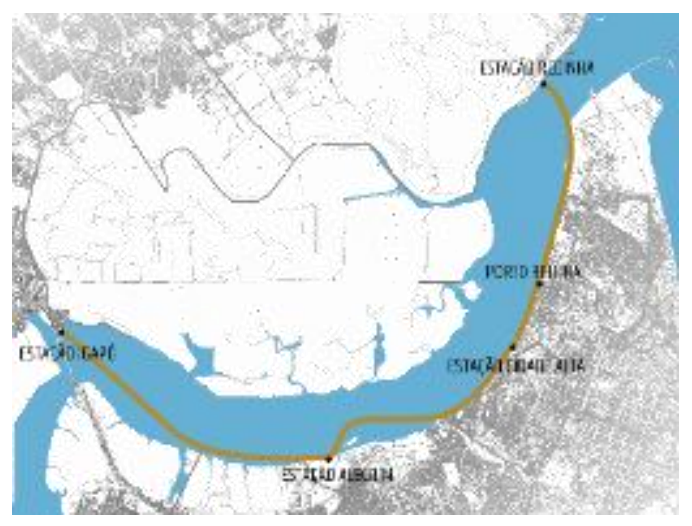

Fonte: Elaborado pelo grupo.

Figura 11: Perspectiva do estacionamento vertical

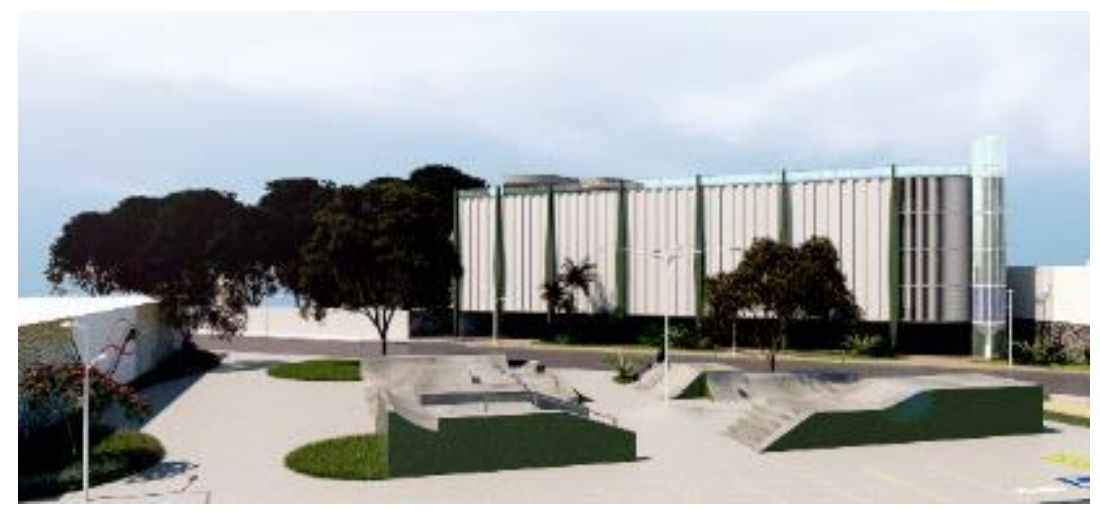

Fonte: Elaborado pelo grupo.

A regularização dos estacionamentos paralelos à via foi necessária para reduzir o impacto no trânsito. Sendo assim, reduziu-se a quantidade de estacionamentos de carros ao longo das vias e foi projetado um estacionamento vertical (Figura 11) de 6 pavimentos, de gestão privada, contemplando em seu programa: bicicletário; lojas; vestiários (no térreo); 4 pavimentos tipo de estacionamento, com 37 vagas cada; restaurante-mirante; e, elevador panorâmico em terreno próximo à área de intervenção, que não impactasse no gabarito do bairro.

Foi pensada uma proposta de identidade visual (Figuras 12 e 13) para o bairro, a fim de evidenciar a identidade do bairro, articulando história e tecnologia. Criou-se uma logomarca para o projeto com cores que representam os eixos de ação de intervenção proposta. 
Cavalcante, E. S.; Marques, E. S. A.; Sampaio, A. L. P.; Cardoso, R. L. A.; Lira, F. O.; Trindade, L. S.; Nascimento, J. B. P.

Figura 12: Síntese da Identidade visual

\section{+Ribeira \\ Descubra os circuitos culturais}
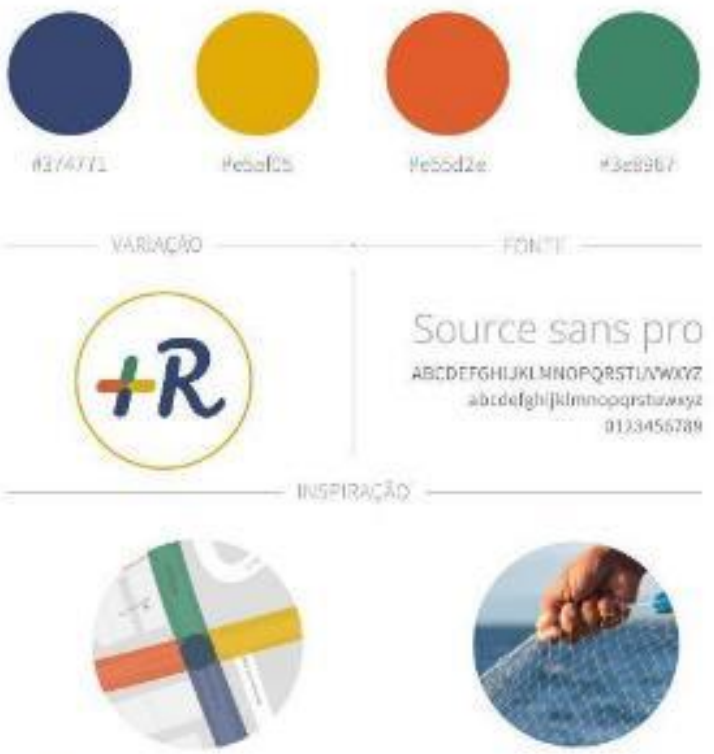

Cruzamento-Econtro dos Cicutos

Iavales de lira \& Dugueda caras
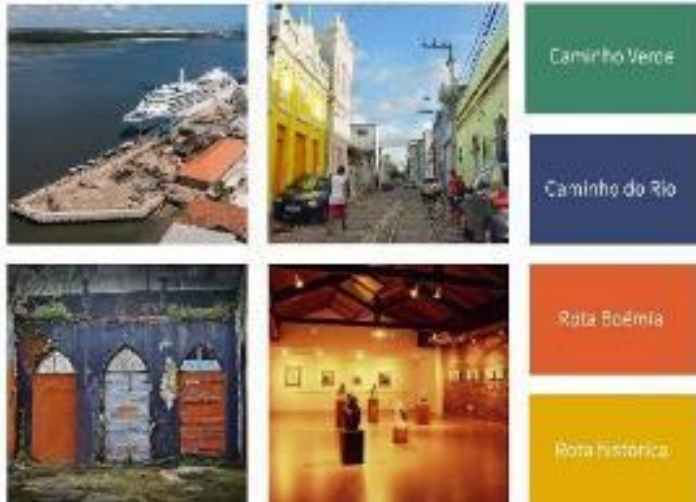

Fonte: Elaborado pelo grupo.
Figura 13: Exemplo de Placa e totem para cada circuito

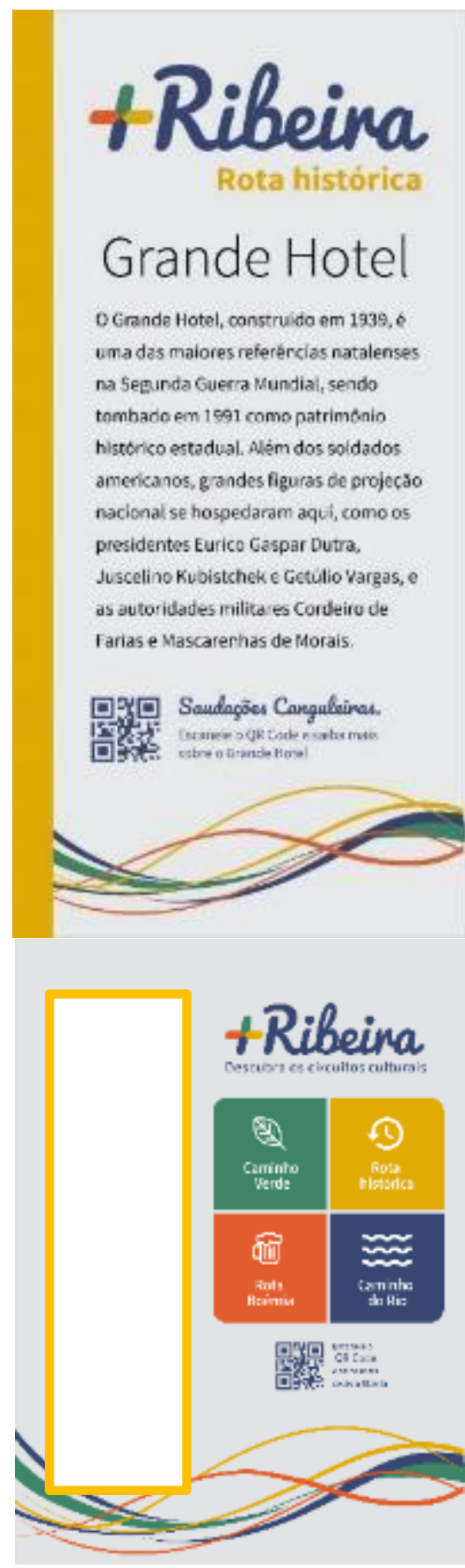

Fonte: Elaborado pelo grupo.

A utilização de totens de informação facilita o deslocamento de pessoas no bairro e também torna mais dinâmica a interação com o lugar, por meio da conectividade proposta, através de QR codes, trazendo informações complementares sobre a Ribeira.

Com o intuito de reduzir o esvaziamento urbano, a proposta contempla a diversificação de usos, incluindo a inserção de novos e o estímulo à habitação (Figura 14), reutilizando prédios desocupados na Ribeira. Para a viabilidade da proposta os incentivos utilizados são baseados no Estatuto das Cidades e na Lei de Operações Urbanas Consorciadas do Centro Histórico de Natal. Sugere-se a isenção de IPTU e do ISSQN em caso de reforma total ou parcial de imóveis, sobretudo para a sua transformação em habitação dentro da Área Tombada do bairro, podendo se estender para a área do entorno do perímetro de tombamento. Além disso, admite-se a construção acima do coeficiente de aproveitamento básico, desde que condicionada ao pagamento de contrapartida por meio da outorga onerosa do direito de construir. 
Figura 14: Proposta de usos - antes $\mathrm{x}$ depois
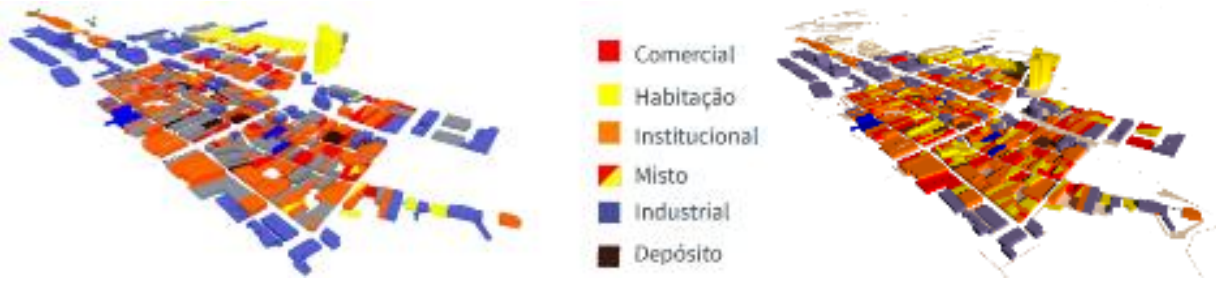

Fonte: Elaborado pelo grupo.

Para tornar o bairro mais aprazível e possibilitar a contemplação da paisagem, foi proposta uma série de mobiliários (figura 15) adequados ao lugar e que proporcionem conforto para melhor circular e permanecer nos espaços públicos da Ribeira. Além disso, o mobiliário pretende favorecer a unidade visual do bairro, fortalecendo a sua identidade (inclusive com circuitos identificados através da cor). A proposta em concreto considera a durabilidade e resistência do material.

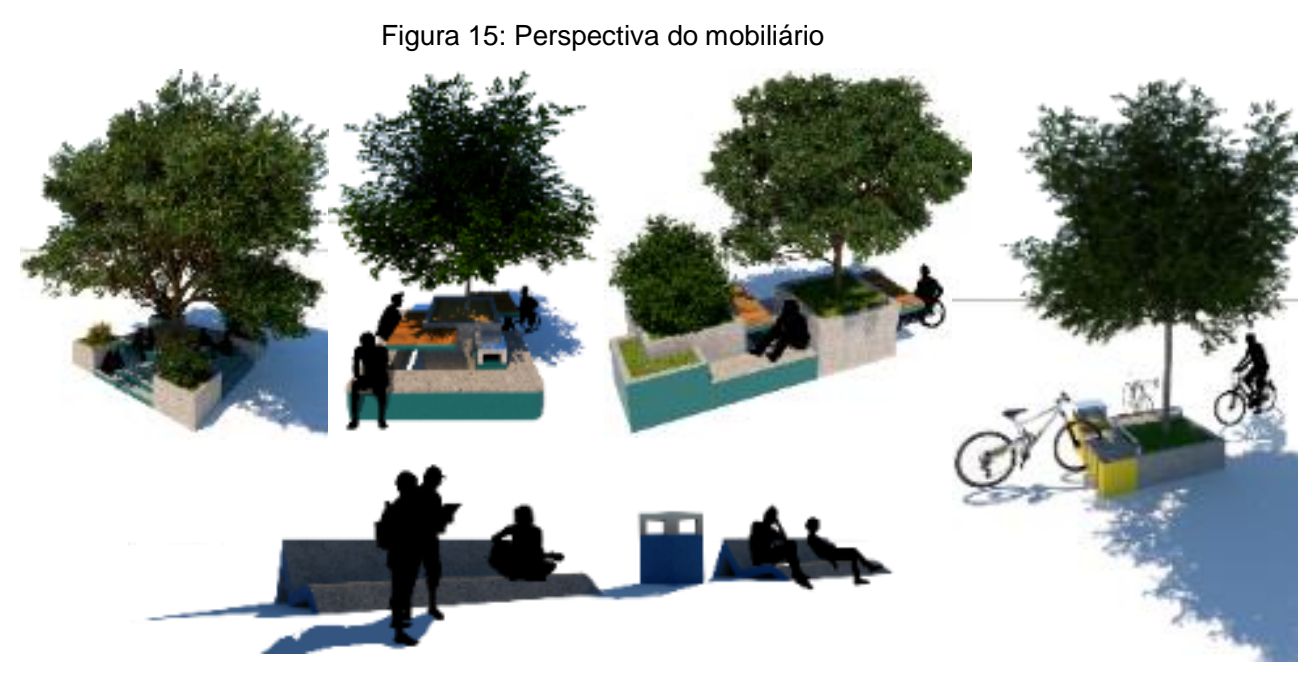

Fonte: Elaborado pelo grupo

Para efeitos orçamentários (Figura 16) de uma operação urbana dessa magnitude, é necessário a criação de um Fundo Especial da Operação gerida pelo Órgão Gestor da operação. Tal fundo deve ter mecanismos de transparência para acompanhamento da sociedade. Esse fundo será mantido a partir da arrecadação de contrapartidas exigidas para benefícios previstos na Operação Urbana, como a outorga onerosa, cobrança de IPTU progressivo e outros mecanismos previstos no Estatuto das Cidades. Além disso, são importantes transferências intergovernamentais e recursos provenientes de instrumentos de parceria entre o Poder Público e a iniciativa privada, provenientes da alienação de imóveis localizados no perímetro da operação e de taxas do licenciamento urbanístico, ambiental e de atividades econômicas no perímetro da operação.

\begin{tabular}{|c|c|c|c|c|}
\hline \multicolumn{5}{|c|}{ Figura 16: Síntese orçamento previsto } \\
\hline 开 & Praças & R\$ 36,290 & A vorzciz & $R \$ 23,955,081^{*}$ \\
\hline \% & Vcegctartẫo & $R \$ 115,207$ & 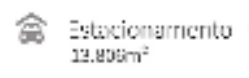 & $R \$ 16,620,048^{* *}$ \\
\hline 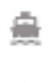 & Hicrobus & 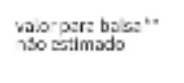 & AH & $\operatorname{RS} 95.3,710$ \\
\hline 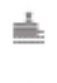 & $\begin{array}{l}\text { Deck } \\
1.545 \eta^{\prime}\end{array}$ & $\mathrm{R} \$ 5,403,450$ & Le Calca:a & $R \$ 3,164,070$ \\
\hline 1 & $\begin{array}{l}\text { Sina liz:ças } \\
329 \text {;uridsdel }\end{array}$ & $\mathrm{RS} 38,400$ & dio & RS 305,280 \\
\hline 5 & $\begin{array}{l}\text { Avea de esporte } \\
1.546 \mathrm{~m}^{2}\end{array}$ & R\$ $1,136,310$ & Total: & $\$ \$ 66,365,749^{*}$ \\
\hline & $\underset{\substack{\text { Comérrio } \\
16 \leq 492 \mathrm{~m}^{2}}}{\cdots}$ & $R \$ 14,6138,303$ & 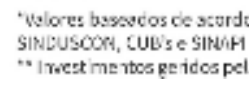 & $\begin{array}{l}\text { corr tatelas do } \\
\text { I ricisasia privada }\end{array}$ \\
\hline
\end{tabular}


Cavalcante, E. S.; Marques, E. S. A.; Sampaio, A. L. P.; Cardoso, R. L. A.; Lira, F. O.; Trindade, L. S.; Nascimento, J. B. P.

A implementação do projeto se daria em 03 fases: curto prazo (05 anos), médio prazo ( 10 anos) e longo prazo (15 anos). Cada etapa direcionaria o tipo de intervenção. A curto prazo (5 anos): Execução de infraestrutura; Ações de educação patrimonial com a comunidade; Criação do fundo especial da Operação Urbana; Alterações nas vias, calçadas e estacionamentos na rua e galpões; Implementação do sistema de drenagem no bairro; Inclusão de equipamentos (mobiliário, ciclovia, paraciclos, etc); Instalação de plataforma de acompanhamento do projeto pela sociedade; Construção de Deck; Implementação de hidrobus; Alocação do Mercado do Peixe na Rua Tavares de Lira; e Implantação parcial dos circuitos (priorizando os circuitos verde e histórico). Em médio prazo (10 anos): Diversificação do bairro; Incentivo e promoção de habitação no bairro, bem como de instalações comerciais variadas; Construção do estacionamento vertical com restaurante na cobertura devido ao aumento do movimento na área; e Promoção do bairro. Por fim, em longo prazo (15 anos): Implementação de políticas públicas no bairro; Consolidação da Ribeira como rota turística; Promoção de uso contínuo dos espaços públicos; Redução do efeito de ilha de calor; Manutenção do Patrimônio Histórico da Ribeira; e Expansão dos investimentos para os bairros Cidade Alta e Rocas.

\section{CONSIDERAÇÕES FINAIS}

$\mathrm{O}+\mathrm{RIBEIRA}$, pois, tem como proposta a retomada do aspecto identitário do bairro, utilizando a rede de pesca como conceito. Cada nó representa um ponto importante na poligonal de intervenção e as linhas são necessárias para conectá-los. Seus bens históricos, seu ar boêmio, seus espaços verdes e seus pontos de ligação com o rio são os nós dessa rede de reconhecimento. Evidenciar esses nós e linhas é essencial para conectar a região à dinâmica da cidade e colocá-la como ponto de interesse turístico e cultural, atraindo novos usuários e moradores.

Sendo "diversidade" uma palavra chave no projeto, distintos usos, acessos e modais tornam-se necessários para instigar mais pessoas a vivenciar as diferentes facetas do bairro. Para tal, foi proposto o reuso de edificações abandonadas e a criação de rotas - boêmia, histórica, verde e o percurso do rio - para promoção cultural e incentivo à ocupação de seus espaços. A mobilidade no bairro por meio desses caminhos é favorecida através dos modais de transporte propostos (hidrobus, a bicicleta e o ônibus). Além disso, é sugerida uma nova identidade visual para a Ribeira, buscando tornar as linguagens arquitetônica e paisagística de mais fácil compreensão. O redesenho de vias e espaços públicos visam priorizar os pedestres, os ciclistas e o transporte público. A expansão desses espaços valoriza a arborização e amplia áreas verdes, melhorando, também, o conforto térmico do lugar. O projeto buscou aliar a dinâmica do mercado com as especificidades locais da Ribeira com o intuito de promover o seu desenvolvimento sustentável do ponto de vista econômico, social e ambiental.

\section{REFERÊNCIAS}

ARAÚJO, B. D. Aplicação de Método de Análise Bioclimática como Ferramenta para Intervenções em Centros Históricos: estudo de caso no bairro da Ribeira em Natal/RN. Dissertação (Mestrado em Arquitetura São Carlos) - Universidade de São Paulo. São Paulo, 2004.

LEFEBVRE, H. O direito à cidade. São Paulo: Centauro, 2001.

SEMURB. Projeto ReHabitar. Secretaria Municipal de Meio Ambiente e Urbanismo, Natal/RN, 2007.

SILVA, H. A. Revitalização urbana de centros históricos: uma revisão de contextos e propostas: a Ribeira como estudo de caso. Dissertação de Mestrado em Arquitetura e Urbanismo. Natal/RN, 2002.

TINOCO, M. B. M.; BENTES SOBRINHA, M. D. P.; TRIGUEIRO, E. B. F. (Orgs). Ribeira: Plano de Reabilitação de Áreas Urbanas Centrais. Natal: EDUFRN, 2008.

NOTA DO EDITOR (*) O conteúdo do artigo e as imagens nele publicadas são de responsabilidade do(s) autor(es). 